\title{
The Role of Vascular Injury and Hemodynamics in Rat Pulmonary Artery Remodeling
}

Yoshihiro Tanaka, ${ }^{\star}$ Daniel P. Schuster, ${ }^{\star}$ Elaine C. Davis, ${ }^{\ddagger}$ G. Alexander Patterson,,${ }^{\S}$ and Mitchell D. Botney ${ }^{\star}$

Departments of $*$ Medicine, ${ }^{\ddagger}$ Cell Biology and Physiology, and ${ }^{\S}$ Surgery, Washington University Medical Center, St. Louis, Missouri 63110

\begin{abstract}
Vascular remodeling in adult human elastic pulmonary arteries is characterized by diffuse neointimal lesions containing smooth muscle cells expressing extracellular matrix genes. Recent studies suggest vascular injury is needed to initiate remodeling and that growth factor mediators participate in the repair response. However, because neointimal formation is only observed in patients with pulmonary artery blood pressures approaching systemic levels, it has been hypothesized that systemic-like hemodynamic conditions are also necessary. To test that hypothesis, subclavian-pulmonary artery anastomoses were created in Sprague-Dawley rats under three different experimental conditions: no accompanying injury, or after monocrotaline or balloon endarterectomy injury.

Pulmonary vascular remodeling was not induced by the subclavian-pulmonary artery anastomosis alone. A nonneointimal pattern of remodeling after mild monocrotalineinduced injury was converted into a neointimal pattern in the presence of the anastomosis. Neointima was also observed after severe, balloon endarterectomy-induced injury even in the absence of anastomosis. Tropoelastin, type I procollagen and TGF- $\beta$ gene expression, and angiotensin converting enzyme immunoreactivity, was confined to the neointima resembling the pattern of gene expression and immunoreactivity in human hypertensive elastic pulmonary artery neointimal lesions. These observations introduce the concepts that the type of injury and the associated hemodynamic conditions can modify the elastic pulmonary artery response to injury. (J. Clin. Invest. 1996. 98:434-442.) Key words: vascular injury - neointima - extracellular matrix • monocrotaline $\cdot$ pulmonary hypertension
\end{abstract}

\section{Introduction}

Vascular remodeling in elastic pulmonary arteries in adults with unexplained pulmonary hypertension is characterized, in part, by active extracellular matrix protein synthesis by vascular smooth muscle-like cells. For example, tropoelastin and type I procollagen are expressed by smooth muscle cells within

Address correspondence to Mitchell D. Botney, M.D., Respiratory and Critical Care Division, Jewish Hospital at Washington University Medical Center, 216 S. Kingshighway Blvd., St. Louis, MO 63110. Phone: 314-454-7117; FAX: 314-454-8605.

Received for publication 11 December 1995 and accepted in revised form 10 April 1996.

J. Clin. Invest.

(c) The American Society for Clinical Investigation, Inc.

0021-9738/96/07/0434/09 \$2.00

Volume 98, Number 2, July 1996, 434-442 a thick, fibrous neointima composed of smooth muscle-like cells, macrophages and extracellular matrix, similar to the atherosclerotic lesions found in systemic arteries (1-4). In contrast to systemic arteries, however, neointimal or atherosclerotic changes are rarely observed in normotensive elastic pulmonary arteries, even in the elderly (1) or in the presence of risk factors for systemic vascular atherosclerosis such as diabetes, tobacco smoke, or hypercholesterolemia (2). One explanation for the absence of neointimal and atherosclerotic lesions in normal pulmonary arteries is their low blood pressure rather than an intrinsic difference between pulmonary and systemic arteries $(2,5,6)$. Consequently, the presence of neointimal and atherosclerotic lesions in hypertensive pulmonary arteries is considered a response to increased blood pressure, regardless of etiology, rather than a primary disorder (6).

Vascular remodeling in elastic pulmonary arteries in experimental animals is also characterized by active extracellular matrix protein synthesis. In contrast to the neointimal remodeling observed in primary pulmonary hypertension, however, a neointima does not form in the elastic pulmonary arteries of these animals. For example, cells adjacent to the vascular lumen express tropoelastin while procollagen is expressed by cells at the medial-adventitial border after monocrotalineinduced injury (7). The reason for the difference between human and experimental patterns of pulmonary vascular remodeling has not been determined. Injury appears to be important since these models require a persistent vascular insult, such as chronic hypoxia in the rat $(8)$ and newborn calf $(9,10)$, monocrotaline intoxication in the rat (11), or chronic air emboli in the sheep (12), to initiate and maintain remodeling. Thus, although both pulmonary and systemic $(13,14)$ arteries appear to require injury to initiate remodeling, whether alterations in pulmonary artery hemodynamics would lead to neointimal formation in these animal models is unknown.

Monocrotaline is a pyrrolizidine alkaloid that induces pulmonary vascular injury. Early pathological changes include pulmonary artery endothelial swelling and blebbing (11) and alveolar inflammatory infiltrates $(15,16)$. The subendothelial space appears widened (17-19), associated with a slight increase in the number of small breaks in the inner elastic lamina compared with normal pulmonary arteries (17). Later changes include progressive vascular remodeling characterized, in part, by increased elastin and collagen protein synthesis and deposition $(11,20,21)$. Although neointimal formation is not observed in pulmonary arteries with normal hemodynamics after monocrotaline-induced injury it is unclear whether neointima would develop in monocrotaline-injured pulmonary arteries subjected to systemic hemodynamics.

In contrast, balloon endarterectomy is a common technique for inducing neointimal formation in the systemic vasculature. In this model of vascular injury the endothelium is mechanically removed and about $25 \%$ of the medial smooth muscle cells are damaged (22). The remaining smooth muscle cells proliferate, migrate to form a neointima, and synthesize 
Table I. Treatment Groups

\begin{tabular}{|c|c|}
\hline Group & Treatment \\
\hline Control $(n=5)$ & No treatment \\
\hline Sham $(n=5)$ & $\begin{array}{l}\text { Harvested } 4 \text { wk after left thoracotomy } \\
\text { alone }\end{array}$ \\
\hline Anastomosis $(n=8)$ & $\begin{array}{l}\text { Harvested } 4 \text { wk after subclavian-pulmonary } \\
\text { artery anastomosis }\end{array}$ \\
\hline Monocrotaline $(n=8)$ & $\begin{array}{l}\text { Harvested } 5 \text { wk after monocrotaline } \\
\text { injection }(60 \mathrm{mg} / \mathrm{kg})\end{array}$ \\
\hline $\begin{array}{l}\text { Monocrotaline } \\
\quad+\text { anastomosis }(n=8)\end{array}$ & $\begin{array}{l}\text { Harvested } 5 \text { wk after monocrotaline } \\
\text { injection }(60 \mathrm{mg} / \mathrm{kg}) \text { and } 4 \mathrm{wk} \text { after } \\
\text { subclavian-pulmonary artery } \\
\text { anastomosis }\end{array}$ \\
\hline Endarterectomy $(n=8)$ & $\begin{array}{l}\text { Harvested } 2 \text { wk after balloon } \\
\text { endarterectomy }\end{array}$ \\
\hline $\begin{array}{l}\text { Endarterectomy } \\
\qquad+ \text { anastomosis }(n=8)\end{array}$ & $\begin{array}{l}\text { Harvested } 2 \text { wk after balloon } \\
\text { endarterectomy and anastomosis }\end{array}$ \\
\hline
\end{tabular}

extracellular matrix proteins such as elastin and type I collagen (23). Whether neointima would form after balloon endarterectomy in pulmonary arteries with normal hemodynamics, or only in the presence of systemic hemodynamics, is also unknown.

The purpose of this study was to determine the pattern of pulmonary vascular remodeling after different types of injury under different in vivo hemodynamic conditions. We hypothesized that injury was required to initiate pulmonary vascular remodeling (no remodeling would be observed in the absence of injury even in the presence of systemic hemodynamics), and that injured pulmonary arteries would only develop neointima in the presence of systemic-like hemodynamics. Specifically, we predicted that the non-neointimal pattern of remodeling found in normal pulmonary arteries after monocrotaline injury would be converted to a neointimal pattern if the pulmonary artery was subjected to systemic-like hemodynamics. Conversely, we predicted that no neointima would develop after balloon endarterectomy in normal pulmonary arteries. To test our hypothesis, we studied the pattern of remodeling in uninjured, monocrotaline or balloon endarterectomy injured pulmonary arteries in vivo in the presence of normal or systemiclike pulmonary hemodynamics.

\section{Methods}

Animal model. Pathogen-free male Sprague-Dawley rats (12 wk old, body weight $310-350$ grams) were used for this experiment. Rats were anesthetized by a subcutaneous injection of ketamine chloride $(0.4 \mathrm{mg})$ and atropine sulphate $(0.1 \mathrm{mg})$, placed in the supine position, and tracheally intubated with a $14 \mathrm{G}$ catheter (Angiocath). Anesthesia was maintained with halothane inhalation $(0.5 \%)$. Ventilation was maintained with a Harvard ventilator (tidal volume $3.0 \mathrm{ml}$, respiratory rate $60 / \mathrm{min}$, PEEP $1.0 \mathrm{~cm} \mathrm{H}_{2} \mathrm{O}$ ). Animals were randomly divided into seven groups: control (no surgery), sham operation, subclavian-pulmonary artery anastomosis, monocrotaline alone, monocrotaline + anastomosis, endarterectomy alone, and endarterectomy + anastomosis (Table I).

For animals receiving an anastomosis, the left pulmonary artery was divided, flushed with heparin $(10 \mathrm{U} / \mathrm{ml})$, and the left subclavian artery anastomosed directly end-to-end to the distal left pulmonary artery (Fig. $1 A$ ) using a cuff technique (24). Particular attention was given to avoid injuring the subclavian or pulmonary arteries. The left
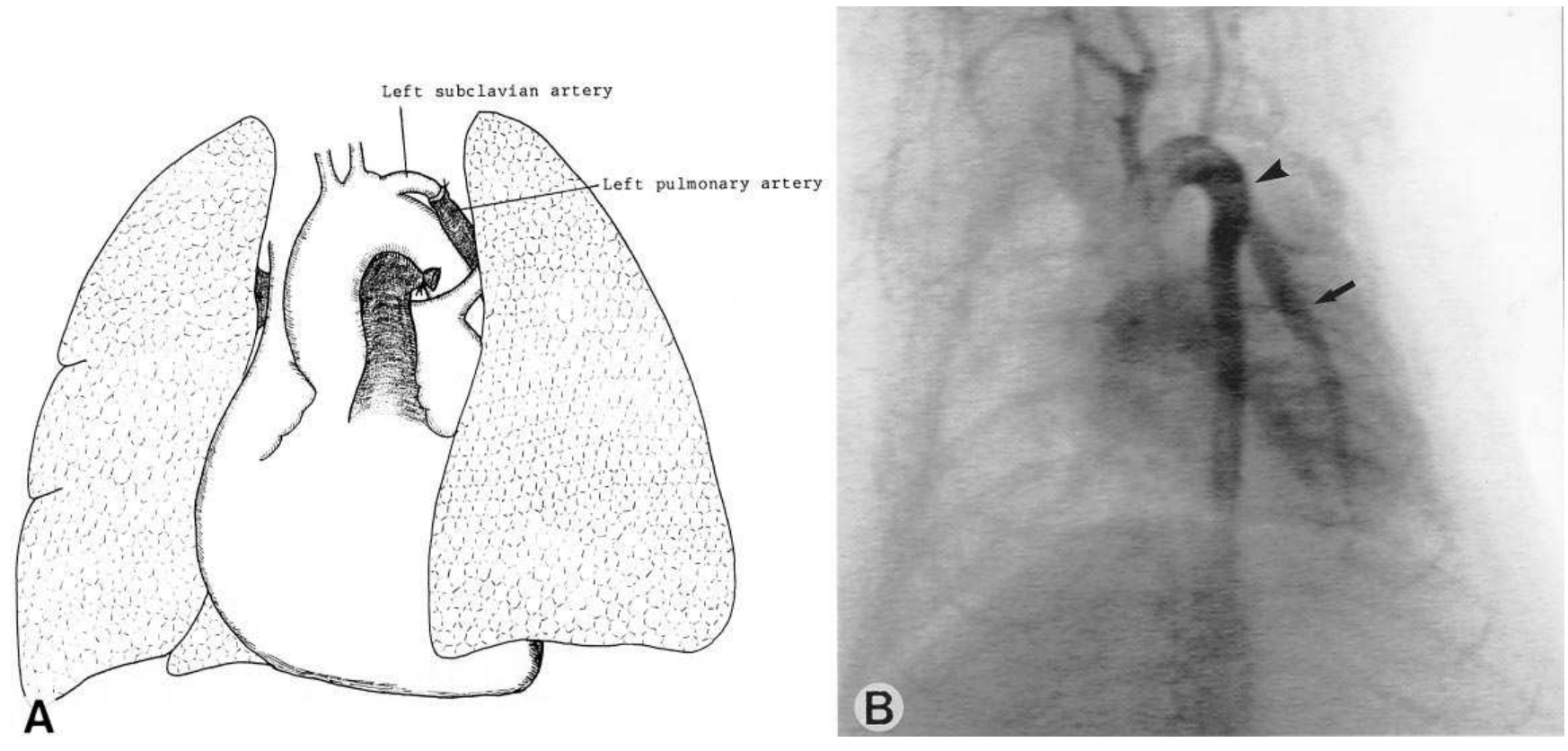

Figure 1. Creation of a subclavian-pulmonary artery anastomosis. The left pulmonary artery is divided and the left subclavian artery is anastomosed directly end-to-end to the distal left pulmonary artery $(A)$. The left lung receives only systemic flows and pressures while the right lung continues to receive its blood supply from the right ventricle. Patency of shunts is confirmed by: $(a)$ observing post-anastomotic dilatation of the pulmonary artery at the time of surgery; $(b)$ confirmation of systemic pressures in the postanastomotic pulmonary artery by direct needle puncture immediately before removal of the lungs; and $(c)$ angiography $(B)$. Arrowhead indicates site of anastomosis while the arrow indicates dilated region of postanastomotic pulmonary artery. 
lung received only systemic blood while the right lung continued to receive its blood supply from the right ventricle. All animals except the control group were allowed to recover with supplemental oxygen ( $2 \mathrm{~L} / \mathrm{min}$ per cage) for the first $24 \mathrm{~h}$ after surgery, and subsequently maintained on room air until death. Patency of shunts was confirmed by: (a) observing postanastomotic dilatation of the pulmonary artery at the time of surgery; $(b)$ confirmation of systemic pressures in the post-anastomotic pulmonary artery by direct needle puncture immediately before harvest of the lungs; and (c) angiography before removal of the lungs (Fig. $1 \mathrm{~B}$ ). All animals received humane care in compliance with the "Principles of Laboratory Animal Care" formulated by the National Society for Medical Research, and the "Guide for the Care and Use of Laboratory Animals" prepared by the National Academy of Science and published by the National Institutes of Health (NIH Publication No. 86-23, revised 1985).

Monocrotaline. Monocrotaline (Sigma Chemical Co., St. Louis, MO) was prepared as described (11). Rats were randomly assigned to a treatment group and injected subcutaneously in the right hindlimb with monocrotaline $(60 \mathrm{mg} / \mathrm{kg})$ or vehicle. Subclavian-pulmonary artery anastomoses were created 1 wk later. Animals were killed $28 \mathrm{~d}$ after surgery ( $5 \mathrm{wk}$ after monocrotaline). In three animals the anastomosis was created first, followed by monocrotaline injection 1 wk later. Animals were killed $28 \mathrm{~d}$ after monocrotaline ( $5 \mathrm{wk}$ after surgery).

Balloon endarterectomy. Left pulmonary artery balloon endarterectomy was performed with a 2 French Fogarty catheter balloon (Baxter Edward) to induce severe vascular injury. The balloon was inserted into the distal lumen of the divided left lower pulmonary artery, inflated with $1 \mathrm{ml}$ air, withdrawn and deflated. This procedure was performed three times. The distal pulmonary artery was then anastomosed to the left subclavian artery.

Endarterectomies were also performed in pulmonary arteries without subsequent anastomosis to the subclavian artery. The balloon was inserted into the left pulmonary artery through a distal branch in a proximal direction, inflated with $1 \mathrm{ml}$ air, partially withdrawn and deflated. This procedure was performed three times. The distal pulmonary artery branch through which the catheter was inserted was then ligated.

Pulmonary artery angiography. To confirm patency of the left subclavian-pulmonary artery anastomoses, angiography was performed with contrast (50\% Conray). Rats were anaesthetized with an intraperitoneal injection of sodium pentobarbital $(0.2 \mathrm{mg})$ and atropine sulfate $(0.1 \mathrm{mg})$, placed in the supine position and tracheally intubated with a $14 \mathrm{G}$ catheter (Angiocath). While spontaneously breathing, a small incision was made in the neck and a $22 \mathrm{G}$ catheter was inserted into the right carotid artery. Angiography was performed during infusion of $3 \mathrm{ml}$ contrast material (Fig. $1 B$ ).
Hemodynamic studies and tissue preparation. Elastic pulmonary arteries were harvested from animals 5 wk after monocrotaline injection (4 wk after surgery) or $2 \mathrm{wk}$ after balloon endarterectomy. Rats were anesthetized by an intraperitoneal injection of sodium pentobarbital $(0.2 \mathrm{mg})$ and atropine sulphate $(0.1 \mathrm{mg})$, placed in the supine position, and tracheal intubation performed with a $14 \mathrm{G}$ catheter (Angiocath). Ventilation was maintained with a Harvard ventilator (tidal volume $3.0 \mathrm{ml}$, respiratory rate $60 / \mathrm{min}$, PEEP $1.0 \mathrm{~cm} \mathrm{H}_{2} \mathrm{O}$ ). Systemic arterial pressure (SAP) was continuously monitored in the right carotid artery throughout the assessment period. After a bilateral transverse mini-thoracotomy through the fourth intercostal space, a $24 \mathrm{G}$ catheter was inserted into the left pulmonary artery distal to the anastomosis under direct visualization and postanastomotic pulmonary arterial pressure (PAP) recorded. After hemodynamic measurements the left lungs of animals with a left subclavian-pulmonary artery anastomosis were flushed with $0.9 \%$ saline infused via the aorta. The left lungs of animals not receiving a subclavian-pulmonary artery anastomosis were flushed with $0.9 \%$ saline infused via the right ventricle. The left pulmonary artery was resected, fixed with neutralbuffered formalin, and embedded in paraffin for in situ hybridization and immunohistochemical staining. After removal of the left pulmonary artery the ratio of right ventricular/left ventricular + septal weight $(\mathrm{RV} / \mathrm{LV}+\mathrm{Sep})$ was determined.

In situ hybridization and immunohistochemistry. In situ hybridization was performed with sense or antisense ${ }^{35}$ S-radiolabeled cRNA probes for type I procollagen, tropoelastin, and TGF- $\beta_{1-3}$ as previously described $(3,25)$.

Immunohistochemistry was performed with antibodies to $\alpha$-smooth muscle actin (Sigma Chemical Co.), macrophages (HAM-56, DAKO), and angiotensin-converting enzyme as previously described (4, 26, 27).

Electron microscopy. Pulmonary arteries, from control rats and rats $12 \mathrm{~h}$ after endarterectomy, were prepared for electron microscopy by cardiac perfusion with $3 \%$ glutaraldehye in $0.1 \mathrm{M}$ sodium cacodylate buffer ( $\mathrm{pH} 7.4)$ as previously described (28). The vessels were dissected into segments and left for $1 \mathrm{~h}$ at $4^{\circ} \mathrm{C}$ in fresh fixative. Tissues were washed in buffer and left overnight at $4^{\circ} \mathrm{C}$ in cacodylate buffer containing $4.2 \%$ sucrose. The next day the tissues were treated sequentially with $1 \%$ osmium tetroxide in buffer, $2 \%$ tannic acid in buffer, and $2 \%$ uranyl acetate in distilled water. Tissues were then dehydrated in a graded series of methanol to propylene oxide, infiltrated and embedded with Epon (SPI Supplies, West Chester, PA). Thin tissue sections were cut on a Reichert ultracut ultramicrotome and counterstained with $7 \%$ methanolic uranyl acetate followed by lead citrate. Sections were examined in a Zeiss 902 transmission electron microscope operating at an accelerating voltage of $80 \mathrm{kV}$.

Table II. Physiologic and Hemodynamic Data

\begin{tabular}{|c|c|c|c|c|c|c|}
\hline Group & pre-BW (g) & post-BW (g) & $\mathrm{sSAP}(\mathrm{mmHg})$ & $\mathrm{sSAP}(\mathrm{mmHg})$ & $\operatorname{mPAP}(\mathrm{mmHg})$ & $\mathrm{RV} / \mathrm{LV}+\mathrm{Sep}$ \\
\hline Control $(n=4)$ & $321 \pm 11$ & $385 \pm 19 *$ & $106 \pm 10$ & $19 \pm 2$ & $11 \pm 2$ & $0.27 \pm .03$ \\
\hline Sham $(n=5)$ & $327 \pm 10$ & $375 \pm 14 *$ & $108 \pm 7$ & $20 \pm 1$ & $14 \pm 1$ & $0.28 \pm .02$ \\
\hline Anastomosis $(n=3)$ & $338 \pm 13$ & $365 \pm 36 *$ & $104 \pm 5$ & $82 \pm 4^{\pi}$ & $75 \pm 2^{\mathscr{I}}$ & $0.27 \pm .02$ \\
\hline Monocrotaline $(n=5)$ & $340 \pm 18$ & $356 \pm 27 *$ & $107 \pm 10$ & $37 \pm 1^{\S}$ & $26 \pm 2^{\S}$ & $0.46 \pm .03^{\S}$ \\
\hline \multicolumn{7}{|l|}{ Monocrotaline } \\
\hline+ anastomosis $(n=5)$ & $344 \pm 26$ & $306 \pm 25^{* \neq}$ & $106 \pm 6$ & $79 \pm 8^{\|}$ & $47 \pm 5^{\|}$ & $0.68 \pm .04 \|$ \\
\hline Endarterectomy $(n=5)$ & $329 \pm 20$ & $343 \pm 21 *$ & ND & ND & ND & $0.30 \pm .03$ \\
\hline Endarterectomy & $346 \pm 37$ & $348 \pm 38$ & ND & ND & ND & $0.30 \pm .04$ \\
\hline
\end{tabular}

pre-BW, body weight prior to monocrotaline injection or endarterectomy; post-BW, body weight 5 wk after monocrotaline injection or 2 wk after endarterectomy. $* P<0.01$ vs. pre-BW; ${ }^{\ddagger} P<0.0001$ vs. all other groups; ${ }^{\circledR} P<0.0005$ vs. control, sham, and anastomosis alone; $\| P<0.0001$ vs. all other groups. " $P<0.0001$ vs. control or sham. sPAP and mPAP measurements made in the left pulmonary artery distal to the anastomosis. Sample size $(n)$ indicates the total number of animals per group with complete hemodynamic data. ND, not done. 


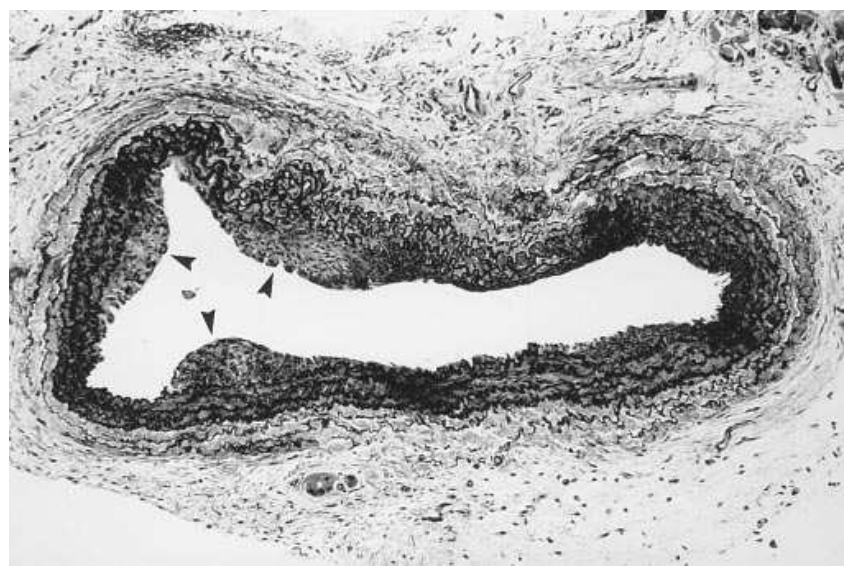

Figure 2. Systemic hemodynamics modifies pulmonary arterial response to injury. Neointima (arrowheads) is present $14 \mathrm{~d}$ after pulmonary arteries are injured by monocrotaline and subjected to systemiclike hemodynamics via subclavian-pulmonary artery anastomosis. The neointima in this elastic pulmonary artery is present diffusely but varies in thickness. Verhoeff-van Gieson stain, $\times 40$.

\section{Results}

\section{Physiologic studies}

There were no significant differences in the preoperative body weights between groups (Table II). After $5 \mathrm{wk}$, the body weights of control, sham-operated, and anastomosis-only animals increased significantly compared with baseline or preoperative weights. There was a minimal increase from baseline in the body weights of rats receiving monocrotaline alone. However, there was a significant decrease in the body weights of rats receiving both monocrotaline and anastomosis.

There were no differences in systemic systolic arterial pressure (sSAP) 4 wks after surgery in the animals receiving monocrotaline alone or monocrotaline + anastomosis compared with control animals, animals with sham operations, or animals with only an anastomosis. Systolic and mean left pulmonary artery pressures (sPAP, mPAP) in animals receiving an anastomosis alone, monocrotaline alone or monocrotaline + anastomosis were significantly higher compared with control animals or animals with sham operations. The sPAP and mPAP in animals receiving monocrotaline + anastomosis approached systemic artery pressures and, therefore, were also significantly greater than sPAP and mPAP in animals receiving monocrotaline alone.

The ratio of right ventricular to left ventricular plus septal weight $(\mathrm{RV} / \mathrm{LV}+\mathrm{Sep})$, an indirect index of pulmonary vascular remodeling, was significantly increased after monocrotaline alone or monocrotaline + anastomosis compared with control animals, animals with sham operations or animals with only an anastomosis. Furthermore, the RV/LV + Sep ratio was significantly increased in the animals receiving monocrotaline + anastomosis compared with monocrotaline alone. There was no significant increase in $\mathrm{RV} / \mathrm{LV}+\mathrm{Sep}$ after anastomosis alone.

\section{Histologic studies}

No injury. The pulmonary arteries of control animals or animals receiving sham anastomoses (thoracotomy alone) appeared normal. There was no evidence of pulmonary vascular remodeling after subclavian-pulmonary artery anastomosis
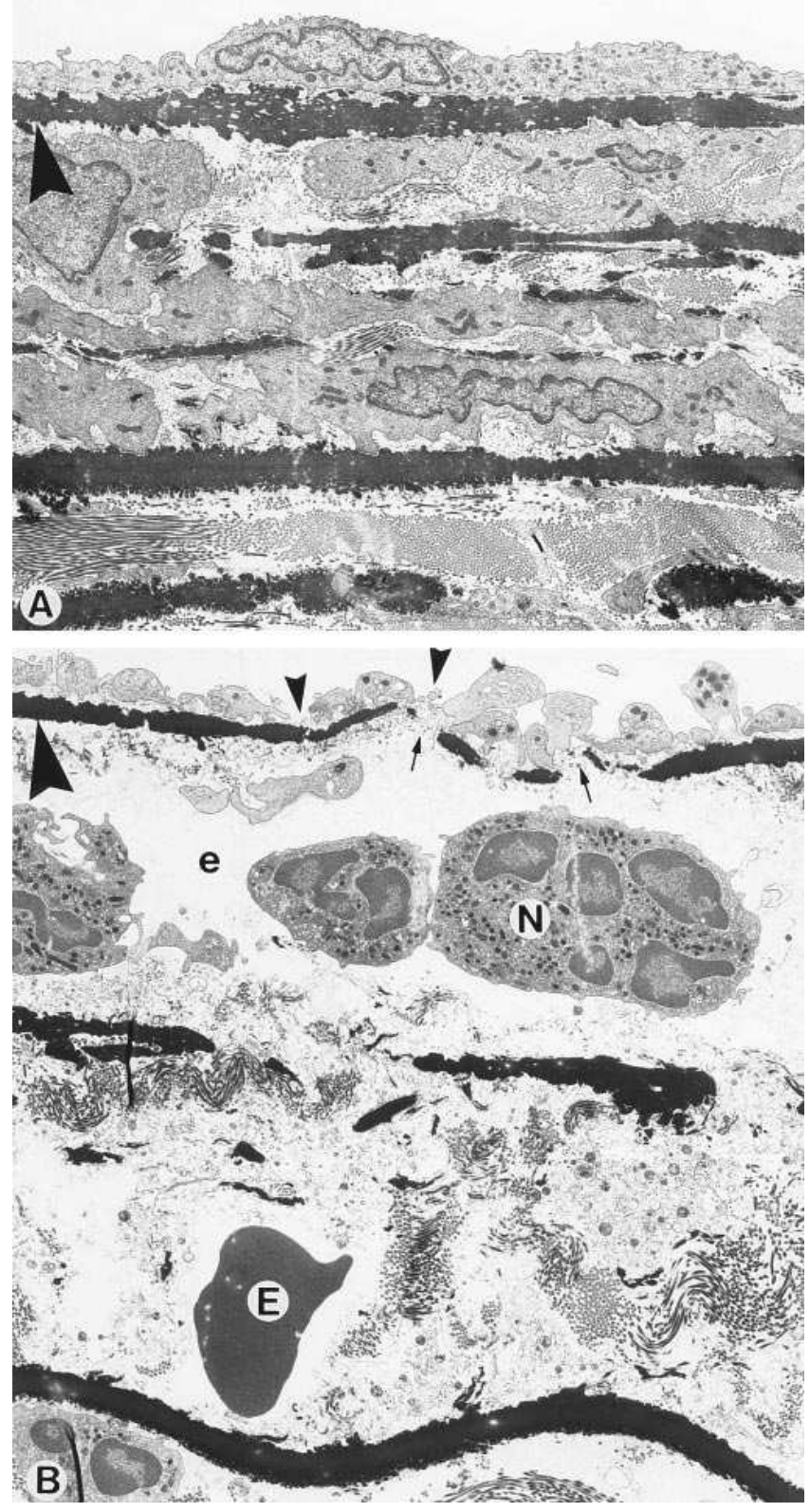

Figure 3. Electron micrograph of damaged pulmonary artery $12 \mathrm{~h}$ after balloon endarterectomy. Left pulmonary artery balloon endarterectomy was performed with a 2 French Fogarty catheter balloon inflated with $1 \mathrm{ml}$ air. The balloon was inserted into the proximal left pulmonary artery, inflated with $1 \mathrm{ml}$ air, withdrawn, and deflated. This procedure was performed three times. Normal pulmonary artery shows intact endothelium, no disruption of inner elastic lamina or other lamellae, no edema, and the absence of neutrophils and erythrocytes $(A)$. Injury after endarterectomy $(B)$ includes endothelial denudation with exposure of sub-endothelial matrix to the vascular lumen (small arrowheads), the internal elastic lamina (large arrowheads) is disrupted (small arrows), edema of the medial layer $(e)$, neutrophil influx $(N)$ and erythrocyte transudation $(E) . \times 5360$.

alone. Histologic examination of the postanastomotic elastic pulmonary arteries showed no evidence of neointimal formation, nor was there evidence of extracellular matrix gene expression by in situ hybridization, up to 6 mo after surgery (data not shown).

Monocrotaline. No neointimal formation was seen in ani- 




Figure 4. Neointimal formation develops in pulmonary arteries after balloon endarterectomy without anastomosis. Left pulmonary artery balloon endarterectomy was performed with a 2 French Fogarty catheter balloon inflated with $1 \mathrm{ml}$ air. The balloon was inserted into the left pulmonary artery through a distal branch, inflated with $1 \mathrm{ml}$ air, partially withdrawn, and deflated. This procedure was performed three times. The distal pulmonary artery branch was then ligated. Extensive neointimal formation is present $2 \mathrm{wk}$ after endarterectomy in this pulmonary artery that was not subjected to systemic-like hemodynamics. Arrowhead indicates inner elastic lamina separating neointima $(i)$ from the medial layer $(m)$. Verhoeff-van Gieson stain, $\times 200$.

mals receiving monocrotaline alone, as previously described (7). Likewise, no neointima was observed if the subclavianpulmonary artery anastomosis was established $1 \mathrm{wk}$ before monocrotaline was administered. However, the left pulmonary arteries from all eight animals receiving monocrotaline followed by subclavian-pulmonary artery anastomosis 1 wk later developed an extensive but patchy neointima (Fig. 2). Immunohistochemistry showed that nearly all neointimal cells were smooth muscle cells with less than $2 \%$ macrophages present (data not shown).

Balloon endarterectomy. Balloon endarterectomy, which induces neointimal formation in systemic arteries, was performed in the left pulmonary artery with and without anastomosis. Electron microscopy after endarterectomy demonstrated ultrastructural damage not observed after monocrotalineinduced injury $(16,17,19)$. Endarterectomy damage included endothelial denudation, severe disruption of the inner elastic lamina, and other elastin lamellae, interlamellar edema, neutrophil influx, and erythrocyte transudation (Fig. 3). Neointimal formation was observed 2 wk after endarterectomy in nonanastomosed pulmonary arteries (Fig. 4) as well as in pulmonary arteries with systemic-like hemodynamics. Immunohistochemistry showed that the cellular composition, $98 \%$ smooth muscle cells with less than $2 \%$ macrophages, was similar to the cellular composition in monocrotaline + anastomosis neointimal lesions.

\section{Gene and protein expression}

Several studies were performed to determine whether gene expression in this neointimal model of elastic pulmonary artery remodeling resembled gene expression observed in remodeling human pulmonary arteries.

Extracellular matrix gene. Tropoelastin and type I procollagen genes are expressed solely by neointimal smooth muscle cells in elastic pulmonary arteries obtained from patients with severe pulmonary hypertension (3). In contrast, after mono- crotaline injury tropoelastin is expressed by cells adjacent to the lumen whereas type I procollagen is expressed at the medial-adventitial border (7). The pattern of extracellular matrix gene expression after monocrotaline + anastomosis or after balloon endarterectomy resembled the pattern seen in human pulmonary arteries. Type I procollagen and tropoelastin gene expression was confined to the neointima (Fig. 5, $A$ and $B$ ). No type I procollagen gene expression was expressed at the medial-adventitial border in monocrotaline-injured pulmonary arteries in the presence of an anastomosis or after balloon endarterectomy with or without anastomosis.

No tropoelastin or type I procollagen gene expression was observed when uninjured pulmonary arteries were exposed to systemic pressures via the anastomosis (data not shown).

$T G F-\beta$. The pattern of TGF- $\beta$ gene expression in remodeling human pulmonary arteries also differs from the pattern of gene expression in pulmonary arteries after monocrotaline injury. All three isoforms of TGF- $\beta$ are found in the neointima of hypertensive elastic pulmonary arteries (25). In contrast, the genes for all three isoforms of TGF- $\beta$ are expressed along the vascular lumen after monocrotaline injury (7). The pattern of TGF- $\beta$ gene expression after monocrotaline injury with surgical anastomosis resembled the pattern seen in human pulmonary arteries since all three isoforms of TGF- $\beta$ were expressed in the neointima (Fig. $5 C$ ).

Angiotensin-converting enzyme. Angiotensin-converting enzyme (ACE) immunoreactivity is increased in endothelial cells of hypertensive human elastic pulmonary arteries compared with endothelial cells of normal pulmonary arteries (27). In addition, neointimal smooth muscle cells are immunoreactive, particularly those cells closer to the endothelial layer. The pattern of ACE immunoreactivity in pulmonary arteries from animals with monocrotaline + anastomosis or with balloon endarectomy was similar to the pattern in human pulmonary arteries. Endothelial ACE immunoreactivity from pulmonary arteries with monocrotaline + surgical anastomosis (Fig. 5 D) 

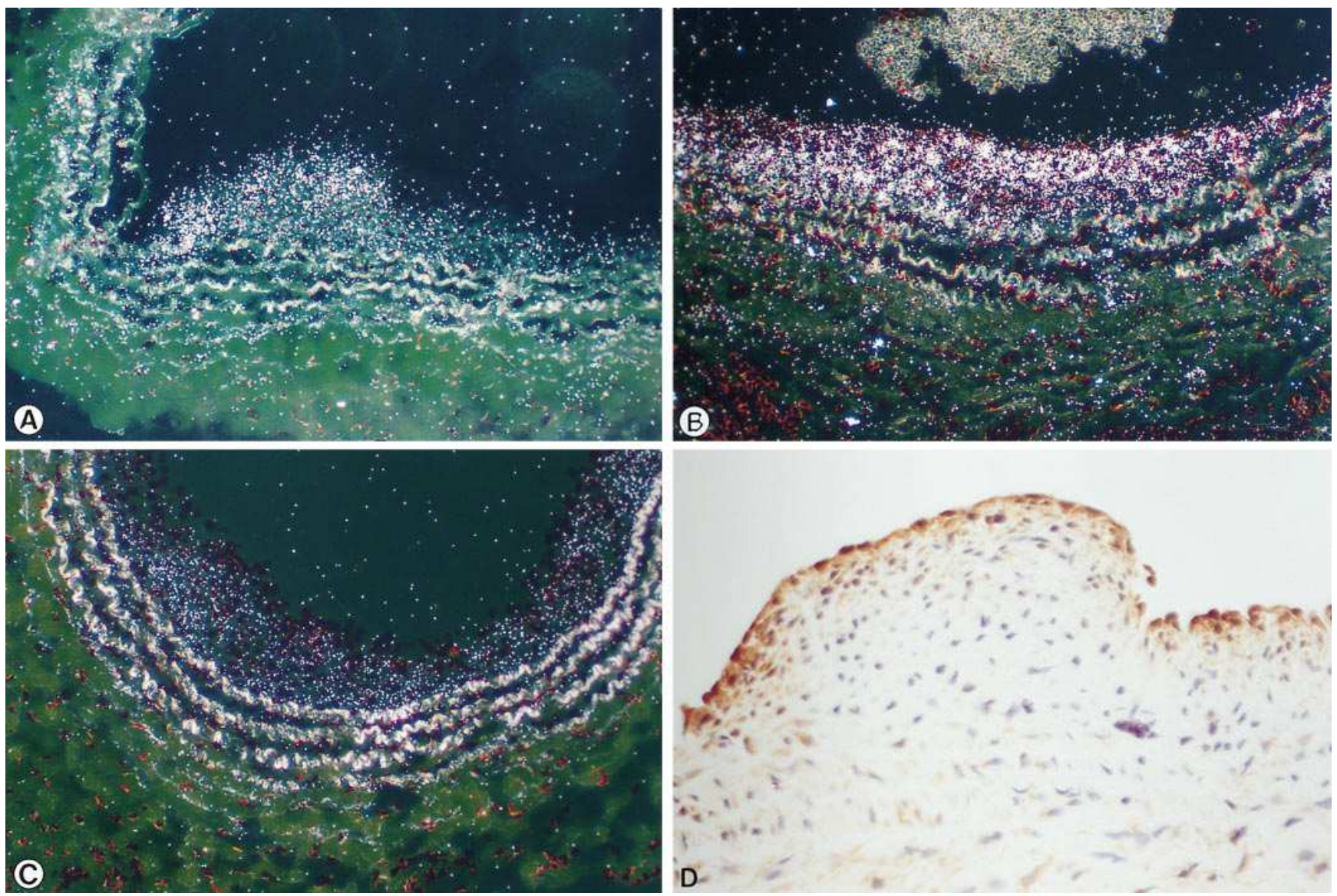

Figure 5. Gene expression in monocrotaline-injured pulmonary arteries subjected to systemic hemodynamics. Type I procollagen $(A)$, tropoelastin $(B)$, and TGF- $\beta 1(C)$ gene expression is confined to the neointima. TGF- $\beta 2$ and TGF- $\beta 3$ gene expression was also confined to the neointima (not shown) similar to TGF- $\beta 1$. No type I procollagen gene expression was seen at the medial-adventitial border, in contrast to monocrotaline alone (7). No signal was seen with sense control probes. ACE immunoreactivity is associated with endothelial cells and neointimal smooth muscle cells closest to the lumen $(D)$. No immunoreactivity was seen with control rabbit serum.

or balloon endarectomy (data not shown) was more intense compared with monocrotaline alone or control animals in which faint ACE expression was confined to the endothelium only. In addition, neointimal cells, particularly those cells closer to the endothelial layer, were also immunoreactive for ACE.

\section{Discussion}

The mechanisms initiating and maintaining pulmonary vascular remodeling remain poorly understood. Several studies with human tissues have provided some insight into possible mediators of remodeling, such as TGF- $\beta(25,29,30)$, angiotensin converting enzyme (27), vascular endothelial growth factor (31), endothelin (32), and nitric oxide (33), although most of our current knowledge is based on animal models of pulmonary vascular remodeling. However, the pattern of vascular remodeling in adult pulmonary vascular remodeling does not closely resemble the pattern seen in animal models. What conditions are responsible for these two different patterns of remodeling is unknown but possibilities include species differences, the duration of remodeling, the type of injury, or hemodynamic factors.
We hypothesized that injured pulmonary arteries would develop neointima only in the presence of systemic-like pressures because of the clinical observation that the elastic pulmonary arteries develop neointima only in severely hypertensive pulmonary arteries. Our results require us to amend this hypothesis and, in addition, provide several insights into the process of pulmonary vascular remodeling. First, this study confirms our previous observation that injury is required to induce vascular extracellular matrix synthesis (7) and suggests that elevated pressure per se is not perceived by the uninjured elastic pulmonary artery as a sufficient stimulus for matrix synthesis. In the absence of injury there was no extracellular matrix gene expression, even in the presence of systemic pressures, for up to six months. Second, hemodynamic conditions can modulate the response to injury. Neointimal formation is seen after monocrotaline-induced injury in the presence of systemic hemodynamics but no neointima is observed with monocrotaline-induced injury in the presence of normal pulmonary hemodynamics. However, if injury is severe enough, such as after balloon endarterectomy, neointima will form even in the presence of normal pulmonary hemodynamics. Third, the pattern of gene expression in this animal model of neointimal formation more closely resembles the pattern of expression seen in remodeling human hypertensive pulmonary arteries. Fourth, 
this study suggests the possibility that pulmonary vascular remodeling in patients may change from a non-neointimal pattern to a neointimal pattern as disease progresses and pulmonary artery hemodynamics change.

Neointimal lesions were not observed if monocrotaline was administered after the anastomosis was performed. While this observation may represent a complex interaction between injury and hemodynamics, there may be a simpler explanation. The initial metabolism of monocrotaline occurs in the liver and includes the formation of monocrotaline pyrroles. Small intravenous doses of one monocrotaline pyrrole, dehydromonocrotaline (MCTP) causes lung toxicity that is virtually identical to that produced by larger doses of monocrotaline (34). Although many monocrotaline pyrroles are quite unstable, MCTP is among the more stable metabolites, with a half-life in rat serum of about 5 seconds (34). Thus, it seems likely that a fraction of MCTP formed in the liver survives passage to the lung to initiate vascular injury. However, in the presence of the subclavian-pulmonary artery anastomosis the left lung is not exposed to the blood immediately leaving the liver. As a result, an insufficient amount of metabolized monocrotaline may be present in the left pulmonary circulation to initiate injury. In addition, young rats appear most susceptible to the effects of monocrotaline with susceptibility decreasing with age since severe damage is seen in other organs besides the lung in very young rats (i.e., $2 \mathrm{wk}$ old) administered monocrotaline, with less severe damage observed in older rats (i.e., $7 \mathrm{wk}$ old) (35). Female rats suffer more non-pulmonary organ damage than male rats of comparable age and die sooner as well. The rats used in these experiments were $12 \mathrm{wk}$ old and male. Thus, an additional explanation for the absence of neointimal formation when anastomosis preceded monocrotaline injury may be the age and gender of the animals used in these experiments.

It is unclear what component of systemic hemodynamics is responsible for neointimal formation in the monocrotaline + anastomosis model of pulmonary vascular remodeling. One explanation is that the left pulmonary artery is exposed to a higher partial pressure of oxygen than normal. Prolonged severe hyperoxia $\left(\mathrm{FiO}_{2}=90 \%\right)$ is well-known for inducing pulmonary hypertension associated with medial hypertrophy in rats (36). Whether exposure of pulmonary arteries to the combination of monocrotaline injury and normal systemic partial pressures of $\mathrm{O}_{2}$ leads to neointimal formation in this model is unknown. Several observations, however, suggest changes in mechanical forces, such as increased stretch, can modulate matrix protein synthesis. For example, pulsatile stretch rapidly induced collagen synthesis in cultured vascular smooth muscle cells (37), and mechanical stretch of isolated pulmonary artery rings rapidly induced tropoelastin and procollagen mRNA expression (38). Intact endothelium was necessary for increased tropoelastin and procollagen mRNA expression, suggesting important interactions occur between the different compartments of the blood vessel. More recently, medial smooth muscle cell type I procollagen immunoreactivity and total pulmonary artery collagen and elastin synthesis were found to increase with increasing stretch in rabbit pulmonary artery strips maintained in organ culture (39). It is unclear, however, whether the increased collagen and elastin synthesis observed in these in vitro studies is related to mechanical forces alone or related to the combination of stretch plus injury incurred during dissection of the vessel. Our results suggest that mechanical stretch alone does not induce matrix synthesis in vivo but that accompanying endothelial or smooth muscle cell injury is necessary.

Shear stress is another component of the mechanical forces acting upon the vascular wall. Systemic arteries tend to normalize to a wall shear stress value of $\sim 15$ dynes $/ \mathrm{cm}^{2}(40)$. Thus, neointimal formation is thought to be one mechanism by which the vessel is able to maintain an appropriate mechanical environment. Shear stress is linearly proportional to the flow rate through the vessel and inversely proportional to the third power of the vessel diameter. The diameter of the postanastomotic pulmonary artery ballooned in all cases to roughly twice its normal size in all cases. Thus, in the absence of any change in blood flow, the shear stress in the postanastomotic pulmonary artery would be reduced to one-eighth the normal vessel shear stress. Although pulmonary artery blood flow increases as the result of the systemic-pulmonic shunt, thereby increasing shear stress, we hypothesize that the net effect is decreased shear stress since shear stress will be more effected by changes in diameter than changes in flow. Thus, one explanation for the absence of pulmonary artery neointimal formation in animal models of pulmonary hypertension despite endothelial injury is the absence of increased mechanical stretch or decreased wall shear stress.

The extent of neointimal formation seems to correlate with the extent of vascular trauma. For example, the rat carotid neointimal cross-sectional area after monofilament endothelial denudation (mild injury) was decreased compared with balloon endarterectomy (severe injury) (41). This was attributed to the greater release of mitogens, such as basic fibroblast growth factor, from medial smooth muscle cells killed by the severe balloon endarterectomy injury. Our results are consistent with the observation that the extent of neointimal formation correlates with the extent of vascular injury. No neointima was observed in the absence of injury. In the presence of monocrotaline injury neointima was observed if the hemodynamic status of the blood vessel was altered, but if the injury was severe enough (balloon endarterectomy) the added influence of mechanical forces was not necessary for matrix synthesis induction and neointimal formation. It is unlikely, however, that such severe injury initiates the remodeling associated with primary pulmonary hypertension.

The presence of erythrocytes in the medial layer suggests an alternative explanation to the release of mitogenic (and profibrotic) factors from damaged medial smooth muscle cells for the initiation of neointimal formation. Plasma factors with mitogenic and profibrotic activity likely enter the damaged blood vessel secondary to disruption of the inner elastic lamina and plasma transudation. Thus, the systemic pressures distal to the anastomosis may promote transudation of plasma factors through the monocrotaline-injured endothelium and the previously demonstrated small breaks in the inner elastic lamina (17).

Although remodeling was not observed with anastomosis alone in this animal model, humans with large left-to-right shunts will develop significant intimal changes if the shunt is not corrected. The pathogenesis of vascular remodeling is unknown, particularly at early stages in these patients, but one possible explanation for this discrepancy is that over a sufficiently long time period the high flow state induces endothelial injury which subsequently leads to remodeling. It is possible vascular remodeling, including neointimal changes, could be initiated in animals with anastomoses only if given sufficient time. Alternatively, the hemodynamic changes after creation 


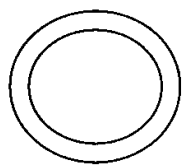

Normal Vessel

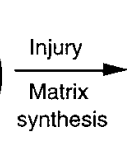

Medial Hypertrophy

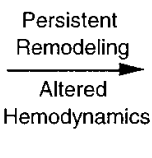

Neointimal formation
Figure 6. The "response" to injury evolves as pulmonary hypertension develops. According to this hypothesis, vascular injury initially induces smooth muscle hypertrophy and hyperplasia, and extracellular matrix protein synthesis, in the medial layer. As medial hypertrophy develops pulmonary artery resistance increases, compliance decreases and local blood flow diminishes at sites of injury and remodeling. With time, the local hemodynamic status is sufficiently altered so that a neointima forms to maintain normal hemodynamics. Patients typically present to medical attention in this later phase of remodeling.

of the subclavian-pulmonary artery anastomosis may not be a sufficient stimulus for remodeling in the rat. Thus, the differences in remodeling between humans with left-to-right shunts and rats with anastomoses only may also reflect an important species difference.

Our results may provide insight into the natural history of pulmonary vascular remodeling in primary pulmonary hypertension as well as provide an explanation for the clinical observation that pulmonary artery neointimal formation is only observed in patients with severe pulmonary hypertension. Based on previous observations, the initial response to injury under normal pulmonary artery hemodynamic conditions is medial remodeling, similar to the pattern seen after monocrotaline injury $(7,17)$. If the vascular injury is limited, remodeling may cease with some residual fibrosis or even complete resolution. However, if remodeling persists, medial hypertrophy develops secondary to smooth muscle hypertrophy and hyperplasia and deposition of extracellular matrix proteins. Blood flow through individual vessels diminishes as pulmonary vascular resistance in those arteries increases. As a result, shear stress in those vessels decreases and neointima formation is induced to maintain normal shear stress (Fig. 6). This process continues until remodeling throughout the entire vascular tree is characterized pathologically by both medial hypertrophy and neointima $(1-3,26,42)$. This hypothesis is consistent with scanning electron micrographs of normal and hypertensive human lobar pulmonary arteries after digestion with formic acid (M. Botney, unpublished observation). This technique, which leaves an indigestible elastin skeleton and therefore provides an "historical" record of the pattern of vascular remodeling, shows increased numbers of thickened elastin interlamellar strands in the medial layer of hypertensive arteries compared with normal arteries even though active remodeling was confined to the neointima at the time the artery was collected (3). Thus, the natural history of remodeling in primary pulmonary hypertension may be that the pattern of vascular remodeling changes with time as the pulmonary hemodynamic conditions change.

In summary, the mechanisms mediating neointimal formation associated with pulmonary vascular remodeling in primary pulmonary hypertension are unknown, but this study suggests vascular injury and abnormal hemodynamics are necessary preconditions for neointimal formation. Although this study was limited to neointimal formation in the elastic pulmo- nary artery, similar preconditions may be required for neointimal formation in the smaller muscular arteries and arterioles.

\section{Acknowledgments}

The authors gratefully acknowledge W. Zhang, T. Toley, J. Roby, and N. Persons for their excellent technical assistance and Dr. Hiroshi Niwa for performing the $\alpha$-smooth muscle actin and macrophage immunohistochemistry.

This work was supported by National Institutes of Health grants HL-48550, HL-41281, HL-02425, and HL-29594, the Alan A. and Edith Wolff Charitable Trust, and a Grant-in-Aid from the American Heart Association.

\section{References}

1. Heath, D., E. Wood, J. Dushane, and J. Edwards. 1959. The structure of the pulmonary trunk at different ages and in cases of pulmonary hypertension and pulmonary stenosis. J. Pathol. Bacteriol. 77:443.

2. Heath, D., E.H. Wood, J.W. DuShane, and J.E. Edwards. 1960. The relation of age and blood pressure to atheroma in the pulmonary arteries and thoracic aorta in congenital heart disease. Lab Invest. 9:259-272.

3. Botney, M.D., L.R. Kaiser, J.D. Cooper, R.P. Mecham, J. Roby and W.C. Parks. 1992. Extracellular matrix protein gene expression in atherosclerotic pulmonary arteries. Am. J. Pathol. 140:357-364.

4. Liptay, M.J., W.C. Parks, R.P. Mecham, J. Roby, L.R. Kaiser, J.D. Cooper and M.D. Botney. 1993. Neointimal macrophages co-localize with extracellular matrix gene expression in human atherosclerotic pulmonary arteries. $J$. Clin. Invest. 91:588-594.

5. Glagov, S., and A.K. Ozoa. 1968. Significance of the relatively low incidence of atherosclerosis in the pulmonary, renal, and mesenteric arteries. Ann. NY Acad. Sci. 149:940-955.

6. Wissler, R.W., and D. Vesselinovitch. 1990. Atherogenesis in the Pulmonary Artery. In The Pulmonary Circulation: Normal and Abnormal. A.P. Fishman, editor. U. Pennsylvania Press, Philadelphia, PA. 245-255.

7. Tanaka, Y., M.L. Bernstein, R.P. Mecham, G.A. Patterson, J.D. Cooper, and M.D. Botney. 1996. Site-specific responses to monocrotaline-induced vascular injury: evidence for two distinct mechanisms of remodeling. Am. J. Respir. Cell Mol. Biol. In Press.

8. Poiani, G.J., C.A. Tozzi, S.E. Yohn, R.A. Pierce, S.A. Belsky, R.A. Berg, S.Y. Yu, S.B. Deak, and D.J. Riley. 1990. Collagen and elastin metabolism in hypertensive pulmonary arteries of rats. Circ. Res. 66:968-978.

9. Stenmark, K.R., J. Fasules, D.M. Hyde, N.F. Voelkel, J. Henson, A. Tucker, H. Wilson, and J.T. Reeves. 1987. Severe pulmonary hypertension and arterial adventitial changes in newborn calves at 4,300 m. Am. J. Physiol. 62: $821-830$.

10. Prosser, I.W., K.R. Stenmark, M. Suthar, E.C. Crouch, R.P. Mecham, and W.C. Parks. 1989. Regional heterogeneity of elastin and collagen gene expression in intralobar arteries in response to hypoxic pulmonary hypertension as demonstrated by in situ hybridization. Am. J. Pathol. 135:1073-1087.

11. Todorovich-Hunter, L., D.J. Johnson, P. Ranger, F.W. Keeley, and M. Rabinovitch. 1988. Altered elastin and collagen synthesis associated with progressive pulmonary hypertension induced by monocrotaline: a biochemical and ultrastructural study. Lab. Invest. 58:184-195.

12. Perkett, E.A., J.M. Davidson, and B. Meyrick. 1991. Sequence of structural changes and elastin peptide release during vascular remodeling in sheep with chronic pulmonary hypertension induced by air embolization. Am. J. Pathol. 139:1319-1332.

13. Ross, R. 1993. Atherosclerosis: a defense mechanism gone awry. Am. J. Pathol. 143:987-1002.

14. Gibbons, G.H., and V.J. Dzau. 1994. The emerging concept of vascular remodeling. N. Engl. J. Med. 330:1431-1438.

15. Stenmark, K.R., M.L. Morganroth, L.K. Remigio, N.F. Voelkel, R.C. Murphy, P.M. Henson, M.M. Mathias, and J.T. Reeves. 1985. Alveolar inflammation and arachidonate metabolism in monocrotaline-induced pulmonary hypertension. Am. J. Physiol. 248:H859-H866.

16. Wilson, D.W., H.J. Segall, L.C.W. Pan, and S.K. Dunston. 1989. Progressive inflammatory and structural changes in the pulmonary vasculature of monocrotaline-treated rats. Microvasc. Res. 38:57-80.

17. Todorovich-Hunter, L., H. Dodo, C. Ye, L. McCready, F. Keeley, and M. Rabinovitch. 1992. Increased pulmonary artery elastolytic activity in adult rats with monocrotaline-induced progressive hypertensive pulmonary vascular disease compared with infant rats with nonprogressive disease. Am. Rev. Resp. Dis. 146:213-223.

18. Rosenberg, H.C., and M. Rabinovitch. 1988. Endothelial injury and vascular reactivity in monocrotaline pulmonary hypertension. Am. J. Physiol. 255: H1484-1491.

19. Guzowski, D.E., and E.D. Salgado. 1987. Changes in main pulmonary 
artery in rats with monocrotaline-induced pulmonary hypertension. Arch. Pathol. Lab. Med. 111:741-745.

20. Kameji, K., H. Otsuka, and Y. Hayashi. 1980. Increase of collagen synthesis in pulmonary arteries of monocrotaline-treated rats. Experientia. 36:441442.

21. Lipke, D.W., S.S. Arcot, M.N. Gillepsie, and J.W. Olson. 1993. Temporal alterations in specific basement membrane components in lungs from monocrotaline-treated rats. Am. J. Respir. Cell Mol. Biol. 9:418-428.

22. Clowes, A.W. M.A. Reidy, and M.M. Clowes. 1983. Mechanisms of stenosis after arterial injury. Lab. Invest. 49:208-215.

23. Nikkari, S.T., H.T. Jarvelainen, T.N. Wight, M. Ferguson, and A.W. Clowes. 1994. Smooth muscle cells expression of extracellular matrix genes after arterial injury. Am. J. Pathol. 144:1348-1356.

24. Mizuta, T., A. Kawaguchi, K. Nakahara, and Y. Kawashima. 1989. Simplified rat lung transplantation using a cuff technique. J. Thorac. Cardiovasc. Surg. 97:578-581.

25. Bahadori, L., J. Milder, L.I. Gold, and M.D. Botney. 1995. Active macrophage-associated TGF- $\beta$ colocalizes with type I procollagen gene expression in atherosclerotic human hypertensive pulmonary arteries. Am. J. Pathol. 146: $1140-1149$.

26. Botney, M.D., M.J. Liptay, L.R. Kaiser, J.D. Cooper, W.C. Parks, and R.P. Mecham. 1993. Active collagen synthesis by pulmonary arteries in human primary pulmonary hypertension. Am. J. Pathol. 143:121-129.

27. Schuster, D.P., E.C. Crouch, W.C. Parks, T. Johnson, and M.D. Botney. Angiotensin converting enzyme expression in primary pulmonary hypertension. Am. J. Resp. Crit. Care Med. In Press.

28. Davis, E.C. 1993. Smooth muscle cell to elastic lamina connecitons in developing mouse aorta - role in aortic medial organization. Lab. Invest. 68 : 89-99.

29. Botney, M.D., W.C. Parks, E.C. Crouch, K. Stenmark, and R.P. Mecham. 1992. TGF- $\beta 1$ is decreased in remodeling hypertensive bovine pulmonary arteries. J. Clin. Invest. 89:1629-1635.

30. Botney, M.D., L. Bahadori, and L.I. Gold. 1994. Vascular remodeling in primary pulmonary hypertension: potential role for transforming growth factor-ß. Am. J. Pathol. 144:286-295.

31. Tuder, R.M., B.E. Flook, and N.F. Voelkel. 1995. Increased gene expression for VEGF and the VEGF receptors KDR/Flk and Flt in lungs exposed to acute or to chronic hypoxia. Modulation of gene expression by nitric oxide. $J$. Clin. Invest. 95:1798-1807.

32. Giaid, A., M. Yanagisawa, and D. Langleben. 1993. Expression of endothelin-1 in the lungs of patients with pulmonary hypertension. N. Engl. J. Med. 328:1732-1739.

33. Giaid, A., and D. Saleh. 1995. Reduced expression of endothelial nitric oxide synthase in the lungs of patients with pulmonary hypertension. N. Engl. J. Med. 333:214-221.

34. Bruner, L.H., L.J. Carpenter, P. Hamlow, and R.A. Roth. 1986. Effect of a mixed function oxidase inducer and inhibitor on monocrotaline pyrrole pneumotoxicity. Toxicol. Appl. Pharmacol. 85:416-427.

35. Schoental, R., and M.A. Head. 1955. Pathological changes in rats as a result of treatment with monocrotaline. Br. J. Cancer 9:229-237.

36. Jones, R., W.M. Zapol, and L. Reid. 1985. Oxygen toxicity and restructuring of pulmonary arteries - a morphometric study. The response to 4 weeks exposure to hyperoxia and return to breathing air. Am. J. Pathol. 121:212-223.

37. Leung, D.Y.M., S. Glagov, and M.B. Mathews. 1977. A new in vitro system for studying cell response to mechanical stimulation. Exp. Cell Res. 109: 285-298.

38. Tozzi, C.A., G.J. Poiani, A.M. Harangozo, C.D. Boyd, and D.J. Riley. 1989. Pressure-induced connective tissue synthesis in pulmonary artery segments is dependent on intact endothelium. J. Clin. Invest. 84:1005-1012.

39. Kolpakov, V., M.D. Rekhter, D. Gordon, W.H. Wang, and T.J. Kulik. 1995. Effect of mechanical forces on growth and matrix protein synthesis in the in vitro pulmonary artery. Circ. Res. 77:823-831.

40. Ku, D.N., and C. Zhu. 1993. The mechanical environment of the artery. In Hemodynamic Forces and Vascular Cell Biology. B. Sumpio, editor. R.G. Landes, Austin, TX. 1-23.

41. Fingerle, J., Y.P.T. Au, A.W. Clowes, and M.A. Reidy. 1990. Intimal lesion formation in rat carotid arteries after endothelial denudation in absence of medial injury. Arteriosclerosis. 10:1082-1087.

42. Pietra, G.G., W.D. Edwards, J.M. Kay, S. Rich, J. Kernis, B. Schloo, S.M. Ayres, E.H. Bergofsky, B.H. Brundage, K.M. Detre et al. 1989. Histopathology of primary pulmonary hypertension: a qualitative and quantitative study of pulmonary blood vessels from 58 patients in the National Heart, Lung and Blood Institute, primary pulmonary hypertension registry. Circulation. 80: 1198-1206. 